\title{
Update on medical expulsive therapy for distal ureteral stones: Beyond alpha-blockers
}

\author{
Derek Bos, MD; Anil Kapoor, MD, FRCSC \\ Division of Urology, Department of Surgery, McMaster University, Hamilton, ON
}

Cite as: Can Urol Assoc J 2014;8(11-12):442-5. http://dx.doi.org/10.5489/cuai.2472

Published online December 15, 2014.

\begin{abstract}
Medical expulsive therapy (MET) has been described as an effective conservative treatment option in the initial management of small distal ureteral stones. Therapies that have been investigated include alpha-blockers, calcium channel blockers, corticosteroids, and most recently phosphodiesterase-5 inhibitors (PDE5) inhibitors. While alpha-blockers are currently the only recommended monotherapy, corticosteroids have received increased attention as a potential useful adjunct in the medical management of distal stones. PDE5 inhibitors are a novel treatment alternative, requiring further investigation. This review provides an overview of recent MET best practices, with a focus on novel therapies beyond alphablockers.
\end{abstract}

\section{Introduction}

Medical expulsive therapy (MET) has been discussed as a reasonable conservative treatment option in the management of distal ureteral stones. Medical management therapies including alpha-blockers, calcium channel blockers, corticosteroids, and phosphodiesterase-5 (PDE5) inhibitors have all been described. The likelihood of a stone passing through the ureter is dependent on several factors, including stone dimensions and ureteral conditions. A wide range of spontaneous passage rates have been reported, ranging from $71 \%$ to $98 \%$ for distal ureteral stones, $<5 \mathrm{~mm}$ and $25 \%$ to $53 \%$ for stones measuring 5 to $10 \mathrm{~mm} .{ }^{1}$ In addition to ureteral spasm, edema is an important factor in arresting ureteral stone passage.

Both alpha-blockers and calcium channel blockers have shown promise in distal ureteral calculi expulsion. The most studied alpha-blocker has been tamsulosin, although a class effect has been suggested. Nifedipine is the only calcium channel blocker that has resulted in improved outcomes. The rationale for using corticosteroids is based on the prin- ciple that the presence of a stone in the ureter creates a mucosal inflammatory reaction, causing various grades of edema. Use of anti-edemic drugs is thought to reduce local ureteral inflammation and facilitate stone expulsion.

Current guidelines on urolithiasis describe the role of MET as a conservative treatment option. MET guidelines concur that alpha-blockers are effective, while there is insufficient evidence to recommend the regular use of calcium channel blockers, corticosteroids, or PDE5 inhibitors as a monotherapy. ${ }^{2}$

\section{Medical expulsive therapy}

\section{Alpha-blockers}

The role of alpha-blockers in MET has been well described..$^{3-6}$ Current best practice guidelines recommend alpha-blockers for the expulsion of distal ureteral stones. Meta-analyses have demonstrated that patients treated with alpha-blockers are more likely to pass stones with fewer episodes of colic. ${ }^{7-8}$ Both the European (EAU) and American Urological Associations (AUA) outline the role of alpha-blockers as a viable option in a select patient population who are comfortable with the approach and where there is no role for immediate surgical stone removal. 2,9

A large meta-analysis by Hollingsworth and colleagues ${ }^{4}$ clearly outlined the benefit of alpha-blockers in MET. Patients treated with alpha-blockers had a $65 \%$ greater likelihood of spontaneous stone passage and a pooled risk ratio of 1.54 (confidence interval [Cl] 1.29-1.85) when compared to control $(p<0.0001)$. The mean stone size ranged from 3.9 to $7.8 \mathrm{~mm}$. The most common side effect reported was transient hypotension at $3.3 \%$ to $4.2 \% .{ }^{4}$ A subsequent review by Seitz and colleagues ${ }^{8}$ analyzed 29 studies including 2419 patients. Pooling demonstrated an overall benefit for stone expulsion with a relative risk of $1.45(\mathrm{Cl} 1.34-1.57)$ and an absolute risk reduction of 0.27 . The mean stone size varied from 4 to $7 \mathrm{~mm}$. Again, transient hypotension was the most 
commonly reported adverse event $(3.3 \%-4.2 \%) .{ }^{8}$

Two recent randomized controlled studies by Al-Ansari and colleagues ${ }^{10}$ and Kaneko and colleagues ${ }^{11}$ validated the efficacy of tamsulosin for distal ureteral calculi. Both studies included a treatment (tamsulosin) and control arm with mean stone sizes ranging from 4.6 to $6.0 \mathrm{~mm}$. Al-Ansari and colleagues showed a rate of stone expulsion 3 times higher in the tamsulosin group, with a relative risk of $2.93 \mathrm{CCl}$ $1.152-7.45) .{ }^{10}$ Stone expulsion rates of $77 \%$ in tamsulosin group and $50 \%$ in control arm were observed $(p=0.002)$ in the Kaneko study. ${ }^{11}$ No significant side effects were documented in either study.

Tamsulosin has been the most studied alpha-blocker in MET. However, a randomized control trial by Yilmaz and colleagues demonstrated that tamsulosin, terazosin, and doxazosin were equally effective in distal stone expulsion in comparison to the control group. ${ }^{12}$ The findings indicate a possible class effect; however, larger studies are required to further validate this small-scale study.

The use of silodosin, as a substitute for tamsulosin, has received increasing attention. Alpha- $1 \mathrm{~A}$ adrenoreceptors are a principal contributor in phenylephrine-induced ureteral contraction in the human isolated ureter. ${ }^{13}$ Dell'Atti compared the effectiveness of silodosin and tamsulosin in the expulsion of distal ureteral stones measuring 4 to $10 \mathrm{~mm} \cdot{ }^{14}$ A total of 136 patients were enrolled in the study, distributed equally between 2 groups. Group 1 received tamsulosin $0.4 \mathrm{mg}$ daily, and group 2 received silodosin $8 \mathrm{mg}$ daily. A significant increase in the expulsion rate was found in patients treated with silodosin $(80.3 \%)$ in comparison to tamsulosin $(61.2 \%)(p=0.003)$. No severe complications were recorded; however, retrograde ejaculation was reported more often in group $2 .^{14}$

A study by Gupta and colleagues supports the belief that silodosin may be superior to tamsulosin in distal ureteral stone expulsion. ${ }^{15} \mathrm{~A}$ total of 100 patients with distal ureteral stones $\leq 1 \mathrm{~cm}$ were enrolled in the study. Group 1 received tamsulosin $0.4 \mathrm{mg}$ daily, whereas group 2 received silodo$\sin 8 \mathrm{mg}$ daily. Stone expulsion rates in group 1 and group 2 were $58 \%$ and $82 \%$ respectively, $p=0.008$. The mean expulsion time was 19.5 days in group 1 and 12.5 days in group $2, p=0.01$. Retrograde ejaculation was more common in patients receiving silodosin. ${ }^{15}$

Alpha-blockers continue to be the mainstay of MET. Studies suggest a relative lower efficacy of stone expulsion rates for $<5 \mathrm{~mm}$ stones than for stones measuring 5 to $10 \mathrm{~mm}$, due to the high spontaneous passage rates of smaller stones.

While tamsulosin has been the most studied, evidence suggests a class effect. The use of silodosin has shown promise in improving expulsion rates, but may be associated with a higher likelihood of retrograde ejaculation.

\section{Corticosteroids}

The use of corticosteroids as a therapeutic option in distal stone expulsion has been discussed in the literature. A number of studies have found favourable results with the use of steroids in stone treatment, however evidence remains poor (Table 1).

A prospective study by Porpiglia and colleagues examined the effects of corticosteroids alone and in conjunction with alpha-blockers in the expulsion of distal ureteral stones. ${ }^{16}$ This study was the first to effectively assess the efficacy of corticosteroids as a monotherapy in stone expulsion. A total of 111 patients were included in the study. Participants were enrolled in 4 of 4 groups, group A received tamsulosin $0.4 \mathrm{mg}$ daily, group $B$ received deflazacort $30 \mathrm{mg}$ daily, group $C$ received both $0.4 \mathrm{mg}$ tamsulosin $+30 \mathrm{mg}$ deflazacort daily, and control group D received only analgesics. The stone expulsion rates for the 4 groups were $60 \%, 37.5 \%, 84.8 \%$, and $33.3 \%$, respectively, with a significant difference observed between

\begin{tabular}{|c|c|c|c|c|c|c|c|}
\hline Publication (year) & Treatment & $\begin{array}{c}\text { No. } \\
\text { patients }\end{array}$ & $\begin{array}{l}\text { Expulsion } \\
\text { rate }\end{array}$ & $\begin{array}{c}\text { Expulsion time } \\
\text { (mean days) }\end{array}$ & $\begin{array}{c}\text { Stone size } \\
\text { (range) }\end{array}$ & $\begin{array}{c}\text { Stone } \\
\text { location }\end{array}$ & Adverse events \\
\hline \multirow{3}{*}{ Porpigli $^{16}$ (2006) } & Tamsulosin & 30 & $60 \%$ & - & \multirow{3}{*}{$\geq 5 \mathrm{~mm}$} & \multirow{3}{*}{ Distal } & Hypotension \\
\hline & Tamsulosin + deflazacort & 33 & $84.5 \%$ & - & & & - \\
\hline & Control & 24 & $33.3 \%$ & - & & & - \\
\hline $\begin{array}{l}\text { Dellabella }{ }^{17} \\
\text { (2005) }\end{array}$ & Tamsulosin & 30 & $90 \%$ & 5 (median) & $\geq 4 \mathrm{~mm}$ & Distal & - \\
\hline \multirow{2}{*}{ Hwang ${ }^{18}$ (2012) } & Control & 66 & $62.1 \%$ & 7.3 & \multirow{2}{*}{$<10 \mathrm{~mm}$} & \multirow{2}{*}{ Distal } & - \\
\hline & Alfuzosin + methylprednisolone & 47 & $82.9 \%$ & 4.4 & & & Dizziness, headache \\
\hline \multirow{2}{*}{ Saita $^{19}(2004)$} & Nifedipine + prednisolone & 25 & $68 \%$ & 6 & \multirow{2}{*}{$<15 \mathrm{~mm}$} & \multirow{2}{*}{ Distal } & Erythema, GI upset \\
\hline & Prednisolone & 25 & $81 \%$ & 10 & & & Pain, GI upset \\
\hline 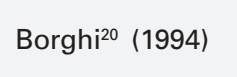 & Nifedipine + methylprednisolone & 43 & $87 \%$ & 11.2 & $<10 \mathrm{~mm}$ & Distal & - \\
\hline
\end{tabular}


group $C$ and the other groups $(p<0.001)$. The mean stone size ranged from 5.71 to $5.96 \mathrm{~mm}$ between groups. The only side effects described were 2 episodes of hypotension in the alpha-blocker alone group. ${ }^{16}$

Further, a study by Dellabella and colleagues evaluated the additional benefit of corticosteroids to alpha-blockers in the treatment of distal ureteral stones. ${ }^{17}$ Patients were randomly assigned to 2 treatment regimens: group 1 with alpha-blocker alone (0.4 $\mathrm{mg}$ tamsulosin) and group 2 with alpha-blocker plus corticosteroid (0.4 mg tamsulosin, deflazacort $30 \mathrm{mg}$ ). A total of 45 patients were included in the study. The median stone size was comparable between the treatment and control arms, at $6.4 \mathrm{~mm}$ and $6.9 \mathrm{~mm}$, respectively. Results revealed no significant difference in stone expulsion rates; however, a shorter time to expulsion was noted in the combined alphablocker and steroid group. The median time to stone expulsion was 120 hours (mean $139.2 \pm 113.8$ ) for 27 patients in group 1 and 72 hours (mean $103.3 \pm 136.2$ ) for 29 patients in group $2(p=0.036)$. Two patients in the steroid treatment arm experienced episodes of dyspepsia. ${ }^{17}$

More recently, Hwang and colleagues reassessed the role of corticosteroids in adjunct to alpha-blockers in the expulsion of distal ureteral stones $<1 \mathrm{~cm} .{ }^{18}$ Patients were divided into 2 groups: control (analgesia only) and treatment (10 mg alfluzosin and $8 \mathrm{mg}$ methylprednisolone). The stone expulsion rate was significantly increased and time to expulsion was significantly decreased in the treatment group. Dizziness and headache were reported in $8.5 \%$ of the treated patients, with no steroid-related side effects noted. ${ }^{18}$

The use of corticosteroids in addition to calcium channel blockers has been examined. Studies by Saita and colleagues and Borghi and colleagues both demonstrated clinical significance in increasing expulsion rates of distal ureteral stones in patients who received combined methylprednisolone and nifedipine therapy. ${ }^{19,20}$ No significant side effects were described in either study.

In the studies reviewed, only short-term courses of corticosteroids were prescribed to avoid many of the adverse effects associated with prolonged corticosteroid therapy. In patients with clinical conditions, such as diabetes, gastric ulcers, or steroid intolerance, corticosteroid therapy should be avoided. While corticosteroids have found to be effective as an adjunct to alpha-blockers and calcium channel blockers, evidence remains insufficient to recommend steroids as a monotherapy, as outlined in the most recent EUA and AUA urolithiasis guidelines. ${ }^{2-9}$

\section{Calcium channel blockers}

Calcium channel blockers and their role in MET continue to be explored. Nifedipine is the only calcium channel blocker that has shown some benefit in stone expulsion..$^{8,16-17}$ Studies have indicated that nifedipine can be effective in reducing renal colic, while improvement in stone expulsion rate has been minimal. Alpha-blockers have been described to be significantly better than nifedipine in facilitating stone passage and relieving renal colic. ${ }^{19,17,21}$ As a result, the most recent EAU guidelines do not recommend calcium channel blockers as a monotherapy for MET. ${ }^{2}$ However, it may be safely used in conjunction with alpha-blockers in the appropriate patient population as side effects have been found to be insignificant. ${ }^{16-17,21-22}$

A systematic review by Seitz and colleagues assessed the effectiveness of calcium channel blocker therapy. ${ }^{8} \mathrm{~A}$ total of 9 studies were reviewed, that included 686 patients. Pooling demonstrated a higher stone expulsion rate among patients treated with calcium channel blockers alone, in comparison to the control group. A relative risk of 1.49 (Cl 1.33-1.66) and absolute risk reduction of 0.26 was observed. No significant side effects were described. ${ }^{8}$

Although calcium channel blockers have shown promise in distal stone expulsion, alpha-blockers have been described as being a more efficacious option. ${ }^{8}$ A systematic review by $\mathrm{Cao}$ and colleagues examined studies directly comparing alpha-blockers to calcium channel blockers in the management of lower ureteral calculi. ${ }^{23} \mathrm{~A}$ total of 7 studies (3897 patients), published between 2004 and 2013, were reviewed, with mean stone diameters measuring 4.7 to $8.85 \mathrm{~mm}$. Pooled estimates were statistically significant between the tamsulosin and nifedipine groups, with a relative risk of $0.81(\mathrm{Cl} 0.75-0.88, p<0.00001)$, indicating that tamsulosin is associated with distinctly better expulsion rates than nifedipine. ${ }^{23}$

\section{Phosphodiesterase- 5 inhibitors}

A novel topic in MET is the utilization of PDE5 inhibitors in stone expulsion. PDE5 inhibitors act by a nitric oxide/cyclic guanosine monophosphate (cGMP)-signaling pathway, resulting in increased levels of cGMP, leading to smooth muscle relaxation in the ureter. ${ }^{24}$ Relaxing effects of ureteral muscle tension have been observed in patients receiving vardenafil, sildenafil, and tadalafil, with the largest effect seen in the vardenafil group. ${ }^{24}$

Kumar and colleagues examined the use of tadalafil in conjunction with tamsulosin and corticosteroid therapy. ${ }^{25}$ The paper was based on the assumption that by combining drugs acting through different mechanisms, better ureteric relaxation and reduction in intramural pressure could be achieved. Patients were divided into 2 groups. Group 1 was given tamsulosin $0.4 \mathrm{mg}$ daily, and group 2 was treated with tamsulosin $0.4 \mathrm{mg}$ and tadalafil $10 \mathrm{mg}$ daily. Both groups received prednisolone $5 \mathrm{mg}$ daily for 1 week. The mean stone size in group 1 and in group 2 measured $7.05 \mathrm{~mm}$ and $6.67 \mathrm{~mm}$, respectively. Stone expulsion rates were increased in group 2, while time to expulsion was decreased. 
However, the results were not clinically significant. Side effects, including headache, dizziness, orthostatic hypotension, and backache, occurred more frequently in group 2 . Improved erectile function was seen in $12.9 \%$ of patients receiving tadalafil. ${ }^{25}$

The use of PDE5 inhibitors and its potential value in MET remain in its infancy. Future studies are required to assess the utility of PDE5 inhibitors in MET.

\section{Conclusion}

Current best practice guidelines recommend alpha-blockers as a conservative management option in the treatment of distal ureteral stones. Corticosteroid therapy, as an adjunct to alpha-blocker therapy, may be effective in improving expulsion rates. Evidence regarding the practice of corticosteroids as a monotherapy for distal ureteral stones remains insufficient. Calcium channel blockers have shown promise, but outcomes remain inferior to alpha-blockers. PDE5 inhibitors have recently been explored, yielding non-significant results. Future studies may look to further validate the use of corticosteroids as an adjunct in stone expulsion, as well as to investigate the efficacy of PDE5 inhibitors.

Competing interests: Dr. Bos declares no competing financial or personal interests. Dr. Kapoor is a member of the Speakers bureau for, and has received grants and honoraria from, Pfizer Oncology, GSK Oncology, Novartis Oncology and Amgen. He has also participated in clinical trials within the past 2 years with NCIC, Pfizer, GSK, Novartis and Amgen.

This paper has been peer-reviewed.

\section{References}

1. Ibrahim Al, Shetty SD, Awad RM, et al. Prognostic factors in the conservative treatment of ureteric stones. Br J Urol 1991;67:358-61. http://dx.doi.org/10.1111/i.1464-410X.1991.tb15161.x

2. Turk C, Knoll T, Petrik A, et al. Guidelines on urolithiasis. European Association of Urology; 2014. http:// www.uroweb.org/gls/pdf/22\%20Urolithiasis_LR.pdf. Accessed December 1, 2014.

3. De Sio M, Autorino R, Di Lorenzo G, et al. Medical expulsive treatment of distal ureteral stones using tamsulosin: A single-center experience. J Endourol 2006;20:12-6. http://dx.doi.org/10.1089/ end.2006.20.12

4. Hollingsworth JM, Rogers MA, Kaufman SR, et al. Medical therapy to facilitate urinary stone passage: A meta-analysis. Lancet 2006;368:1171-9. http://dx.doi.org/10.1016/S0140-6736(06)69474-9

5. Michel MC, de la Rosette JJMCH. $\alpha$-Blocker treatment of urolithiasis. Eur Urol 2006;50:213-4. http:// dx.doi.org/10.1016/j.eururo.2006.02.047
6. Parsons JK, Hergan LA, Sakamoto K, et al. Efficacy of $\alpha$-blockers for the treatment of ureteral stones. J Urol 2007;177:983-7. http://dx.doi.org/10.1016/i.juro.2006.10.023

7. Liatsikos EN, Katsakiori PF, Assimakopoulos K, et al. Doxazosin for the management of distal-ureteral stones. J Endourol 2007;21:538-41. hittp://dx.doi.org/10.1089/end.2006.0107

8. Seitz C, Liatsikos E, Porpiglia F, et al. Medical therapy to facilitate the passage of stones: What is the evidence? Eur Urol 2009;56:455-71. http://dx.doi.org/10.1016/i.eururo.2009.06.012

9. Preminger GM, Tiselius HG, Assimos G, et al. Management of ureteral calculi: EAU-AUA nephrolithiasis panel; 2007. htrp://www.auanet.org/education/guidelines/ureteral-calculi.ffm. Accessed December 1, 2014.

10. Al-Ansari A, Al-Naimi A, Alobaidy A, et al. Efficacy of tamsulosin in the management of lower ureteral stones: A randomized double-blind placebo-controlled study of 100 patients. J Urol 2010;75:4-7. http:// dx.doi.org/10.1016/i.urology.2009.09.073

11. Kaneko T, Matsushima H, Morimoto H, et al. Efficacy of low dose tamsulosin in medical expulsive therapy for ureteral stones in Japanese male patients: A randomized controlled study. Int Urol 2010;17:462-5. http://dx.doi.org/10.1111/ji.1442-2042.2010.02499.x

12. Yilmaz E, Batislam E, Basar $M$, et al. The comparison and efficacy of 3 different alphal-adrenergic blockers for distal ureteral stones. J Urol 2005;173:2010-2. http://dx.doi.org/10.1097/01. ju.0000158453.60029.0a

13. Sasaki S, Tomiyama Y, Kobayashi S, et al. Characterization of a (1)-adrenoceptor subtypes mediating contraction in human isolated ureters. Urology 2011;77:762.e13-7.

14. Dell'Atti L. Silodosin versus tamsulosin as medical expulsive therapy for distal ureteral stones: A prospective randomized study. Urologia 2014. http://dx.doi.org/10.5301/uro.5000083

15. Gupta S, Lodh B, Singh AK, et al. Comparing the efficacy of tamsulosin and silodosin in the medical expulsion therapy for ureteral calculi. J Clin Diagn Res 2013;7:1682-4

16. Porpiglia F, Vaccino D, Billia M. Corticosteroids and tamsulosin in the medical expulsive therapy for symptomatic distal ureter stones: Single drug or association? Eur Urol 2006;50:339-44. http://dx.doi. org/10.1016/i.eururo.2006.02.023

17. Dellabella M, Milanese G, Muzzonigro G. Randomized trial of the efficacy of tamsulosin, nifedipine and phloroglucinol in medical expulsive therapy for distal ureteral calculi. J Urol 2005;174:167-72. http:// dx.doi.org/10.1097/01.ju.0000161600.54732.86

18. Hwang E, Hwang I, Yu H, et al. Effects of alfluzosin with methylprednisolone for spontaneous expulsion and pain control of lower ureteral stone. Urol Res 2012;40:605-9. hittp://dx.doi.org/10.1007/ s00240-012-0482-2

19. Saita A, Bonaccorsi $A$, Marchese $F$, et al. Our experience with nifedipine and prednisolone as expulsive therapy for ureteral stones. Urol Int 2004;72(Suppl 1):43-5. http://dx.doi.org/10.1159/000076591

20. Borghi L, Meschi T, Amato F, et al. Nifedipine and methylprednisolone in facilitating ureteral stone passage: A randomized, double- blind, placebo-controlled study. J Urol 1994;152:1095-8.

21. Ye Z, Yang H, Li H, et al. A multicentre, prospective, randomized trial: Comparative efficacy of tamsulosin and nifedipine in medical expulsive therapy for distal ureteric stones with renal colic. BJU Int 2011;108:276-9. http://dx.doi.org/10.1111/i.1464-410X.2010.09801.x

22. Porpiglia $F$, Ghignone $G$, Fiori $C$, et al. Nifedipine versus tamsulosin for the management of lower ureteral stones. J Urol 2004;172:568-71. http://dx.doi.org/10.1097/01.ju.0000132390.61756.ff

23. Cao D, Yang Lu, Liu L. A comparison of nifedipine and tamsulosin as medical expulsive therapy for the management of lower ureteral stones without ESWL. Scientific Reports, 2014. http://www.nature.com/ srep/2014/140611/srep05254/full/srep05254.html. Accessed December 1, 2014.

24. Gratzke C, Uckert S, Reich 0 , et al. PDE5 inhibitors. A new option in the treatment of ureteral colic? Urologe A 2007;46:1219-23. htrp://dx.doi.org/10.1007/s00120-007-1409-3

25. Kumar S, Kumar J, Swati A, et al. Comparative efficacy of tamsulosin versus tamsulosin with tadalafil in combination with prednisolone for the medical expulsive therapy of lower ureteral stones: A randomized trial. Korean J Urol 2014;55:196-200. http://dx.doi.org/10.4111/kju.2014.55.3.196

Correspondence: Dr. Anil Kapoor, G344 - McMaster Institute of Urology, 50 Charlton Ave. E, Hamilton, 0N L8N 4A6; akapoor@mcmaster.ca 